\title{
Hydroxylated PCB Metabolites and PCBs in Serum from Pregnant Faroese Women
}

\author{
Britta Fängström, ${ }^{1}$ Maria Athanasiadou, ${ }^{1}$ Philippe Grandjean, ${ }^{2,3}$ Pál Weihe, ${ }^{2,4}$ and Åke Bergman \\ ${ }^{1}$ Department of Environmental Chemistry, Stockholm University, Stockholm, Sweden; ${ }^{2}$ Institute of Public Health, University of Southern \\ Denmark, Odense, Denmark; ${ }^{3}$ Department of Environmental Health, Boston University School of Public Health, Boston, Massachusetts, \\ USA; ${ }^{4}$ Faroese Hospital System, Tórshavn, Faroe Islands
}

\begin{abstract}
In the Faroe Islands in the North Atlantic, the traditional diet includes pilot whale meat and blubber and other marine food. Fatty fish and blubber of mammals may contain high concentrations of organohalogen substances (OHSs). Elevated levels of OHSs have been reported from the Faroe Islands, first documented in breast milk samples obtained in 1987. The aim of this study was to determine the concentrations of hydroxylated polychlorinated biphenyls (OH-PCBs) and polychlorinated biphenyls (PCBs) in serum samples from pregnant Faroese women known to differ in their dietary habits. High concentrations of $\mathrm{OH}-\mathrm{PCB}$ and $\mathrm{PCB}$ s were found in part of the human serum samples analyzed, and the relative OH-PCB and $\mathrm{PCB}$ congener distributions were similar to those observed elsewhere. There was a wide span between the lowest and highest $\mathrm{OH}-$ PCB and PCB concentrations in the serum samples analyzed, with ranges of $19-1,800 \mathrm{ng} / \mathrm{g}$ lipid weight (lw) and 150-22,000 ng/g lw, respectively. The ratio of $\Sigma \mathrm{OH}-\mathrm{PCB} / \Sigma \mathrm{PCB}$ averaged about $10 \%$ and varied little. 4-Hydroxy-2, $2^{\prime}, 3,4^{\prime}, 5,5^{\prime}, 6$-heptachlorobiphenyl was the most abundant $\mathrm{OH}-\mathrm{PCB}$ metabolite in all samples analyzed, with four other OH-PCB congeners as dominating metabolites in the serum. More than 25 additional $\mathrm{OH}-\mathrm{PCB} s$ were indicated. This study confirms the presence of high concentrations of organohalogen substances in populations or areas far removed from their sources. Key words: Faroe Islands, marine foods, polychlorinated biphenyls, polychlorobiphenylols, pregnancy. Environ Health Perspect 110:895-899 (2002). [Online 26 July 2002]

http://ehpnet1.niehs.nih.gov/docs/2002/110p895-899fangstrom/abstract.html
\end{abstract}

Polychlorinated biphenyls (PCBs) remain an important class of environmental contaminants even though major legislative measures were taken by most industrialized countries in the early 1970 s to stop their production and to restrict most their uses thereof (1). 2,2Bis(4-chlorophenyl)-1,1,1-trichloroethane $\left(4,4^{\prime}-\mathrm{DDE}\right)$ and persistent PCB congeners are in general and still the most abundant pollutants in wildlife and humans, although recent decreases have been reported $(2,3)$. High concentrations of these substances have been determined even in populations living in remote areas $(4,5)$, including people from the Faroe Islands, as first documented by analyses of four pools of human breast milk sampled from a birth cohort in 1987 (6). Similarly high PCB and 4,4' -DDE concentrations were obtained from a second Faroese birth cohort from 1994 (7). People who have a high consumption of fatty fish and live closer to the sources of contamination have high levels of PCBs and DDE (8).

Halogenated phenolic compounds (HPCs) are known to be strongly retained in human and wildlife blood (9), and these metabolites may be present in concentrations only slightly lower than those of the parent compounds (10-12). Among those compounds, a large number of polychlorobiphenylols (OH-PCBs) have earlier been reported in blood from humans, birds, seals, and polar bears (9-17). The concentration of the OH-PCBs may exceed $10 \%$ of the total $\mathrm{PCB}$ concentration in human serum $(5,9,12)$. As many as $38 \mathrm{OH}-\mathrm{PCB}$ have been identified in human plasma (10), but only a few of these make up the major proportion of the $\mathrm{OH}-\mathrm{PCB}$ concentrations in the human blood. OH-PCBs are formed via cytochrome P450-mediated oxidation of individual PCB congeners, and those being retained in the blood are metabolites of those that are most strongly accumulated in lipids - the most persistent PCB congeners. Several of the $\mathrm{OH}$ $\mathrm{PCB}$ s compete with thyroxine $\left(\mathrm{T}_{4}\right)$ for its binding to transthyretin (TTR) (18). One of the major OH-PCBs, 2,3,3',4',5-pentachloro-4-biphenylol (4-OH-CB107), which has been identified in human blood (9), appears to possess adverse endocrine-related toxicity (19). OH-PCB metabolites are generally more hydrophilic than the parent compound and are therefore more easily eliminated from the body than their parent PCB congeners. Still, the physicochemical properties of some of the OH-PCBs suggest retention rather than excretion (9). However, it is not known whether the OH-PCBs occur along with the parent $\mathrm{PCB}$ congeners at similarly increased concentrations in subjects with high exposure to lipophilic contaminants from seafood as those with a lower exposure.

The Faroe Islands in the North Atlantic have a relatively uniform population of about 45,000 inhabitants. Besides fish (mainly cod), pilot whale blubber and meat have traditionally been part of their diet ( 6 ). Seabirds and their eggs may also be included in the Faroese diet for part of the year. Certain types of marine food, especially fatty fish and blubber of mammals living in polluted waters, contain high concentrations of organohalogen substances (OHSs) (1). Persons who frequently consume contaminated seafood therefore exhibit increased concentrations of OHSs in serum and adipose tissue $(8,12)$.

Our aim in this study was to determine the concentrations of $\mathrm{OH}-\mathrm{PCB}$ and $\mathrm{PCB}$ in serum samples from pregnant Faroese women. Women were therefore selected to represent different exposure levels associated with different intakes of traditional food.

\section{Materials and Methods}

Samples. Serum samples were collected at the National Hospital in Tórshavn, Faroe Islands, in connection with the formation of a cohort of 182 mother-child pairs in 1994-1995. We collected maternal serum samples at the last antenatal consultation, approximately the 32nd week of pregnancy. Milk was obtained at 3-4 days postpartum and analyzed for major PCB congeners ( 7 ). Based on these results, we selected 36 subjects to represent the full range of PCB exposures. Stored serum was retrieved for analysis. We used a brief nutritional questionnaire to obtain information about the frequency of blubber and whale meat meals during pregnancy (number of meals per month). Although we made no attempt to assess lifetime intake levels, we categorized the subjects with respect to their recent consumption of

Address correspondence to B. Fängström, Department of Environmental Chemistry, Stockholm University, S-106 91 Stockholm, Sweden. Telephone: 46-8163995. Fax: 46-8-163979. E-mail: britta.fangstrom@ mk.su.se

We are grateful to B. Heinzow for allowing us to use the milk PCB results for identification of the women selected for this study.

The project was financially supported by grants from the Nordic Arctic Research program (Nordic Council of Ministers), the European Commission (Environment and Climate Research Program, EV 5V-CT940472), the U.S. National Institute of Environmental Health Sciences (ES06894), MISTRA research project Dnr. 99607, and the Swedish Environmental Protection Agency.

Received 16 October 2001; accepted 19 February 2002 . 
pilot whale blubber as follows: none/low = $0-1$ blubber meals/month $(n=21)$; moderate/high $=2-8$ blubber meals $/$ month $(n=$ 15). This stratification provided reasonable numbers of subjects in each category.

Chemicals. The reference compounds, the abbreviations by which they are designated, and their sources of origin are given in Table 1 . Hexane $(\mathrm{Hx})$ and dichloromethane (DCM) were pesticide grade (Fisher Scientific, Leicestershire, UK). Potassium chloride, hydrochloric acid, sulfuric acid (Merck, Darmstadt, Germany), and potassium hydroxide (Eka Nobel, Bohus, Sweden) were all of pro analysis (p.a.) quality. 2-Propanol (p.a. grade; Prolabo, Cedex, France) and methyl tert-butyl ether (HPLC-grade; Rathburn, Walkerburn, Scotland) were glass distilled before use. Silica gel $(<0.063 \mathrm{~mm})$ was purchased from Macherey-Nagel (Düren, Germany) and activated before use. Deionized water was produced in an Elga stat apparatus (Elga Ltd., Wycombe, England). Diazomethane was prepared from $N$-methyl- $N$-nitroso- $P$-toluenesulfonamide (Diazald) obtained from SigmaAldrich (Steinheim, Germany) (20).

Instruments. We used a vacuum centrifuge evaporator (Genevac SF50; Saler Development Ltd., Ipswich, UK) to evaporate solvents. A table centrifuge (Wifug Ltd., Bradford, England) operated at $3000 \mathrm{rpm}$ was used to promote efficient phase separation.

Gas chromatography (GC) analyses were performed on a Varian 3400 gas chromatograph, equipped with a Varian 8200 autosampler (Varian Associates, Walnut Creek, CA, USA), an electron capture detector (ECD), and a split-splitless injector operated in the splitless mode. Hydrogen was used as carrier gas and nitrogen as make-up gas. For PCB analysis a DB-5 column $(30 \mathrm{~m} \times 0.25 \mathrm{~mm}$ internal diameter and $0.25 \mu \mathrm{m}$ film thickness; J\&W Scientific, Folsom, CA, USA) was used. The GC temperature program was initiated at $80^{\circ} \mathrm{C}(2 \mathrm{~min})$ and then increased by $10^{\circ} \mathrm{C} / \mathrm{min}$ to $300^{\circ} \mathrm{C}(10 \mathrm{~min})$. The injector temperature was $250^{\circ} \mathrm{C}$ and the detector temperature $360^{\circ} \mathrm{C}$. The analysis on the phenolic substances was performed on a CP-Sil 8-column $(25 \mathrm{~m} \times 0.15 \mathrm{~mm}$ internal diameter and $0.12 \mu \mathrm{m}$ film thickness; Chrompack, EA Middelburg, The Netherlands). The column temperature was programmed as follows: $80^{\circ} \mathrm{C}(2 \mathrm{~min}), 50^{\circ} \mathrm{C} / \mathrm{min}$ to $200^{\circ} \mathrm{C}, 1^{\circ} \mathrm{C} / \mathrm{min}$ to $230^{\circ} \mathrm{C}$, and $30^{\circ} \mathrm{C} / \mathrm{min}$ to $330^{\circ} \mathrm{C}(3 \mathrm{~min})$. The injector temperature was $280^{\circ} \mathrm{C}$ and the detector temperature $360^{\circ} \mathrm{C}$. We collected and processed data using a PC-based ELDS Pro v2.0 system (Chromatograhic Data System AB, Stockholm, Sweden).

Cleanup procedure. The extraction and cleanup procedure of the OHS from serum has been described in detail elsewhere (21). The surrogate standards, CB189 (4 ng) and
4-OH-CB193 (2 ng), were added before extraction. We determined the extracted lipid amount gravimetrically. The cleanup produced two fractions, one containing neutral and the other containing the phenolic substances (21). In addition to the cleanup described in the method, the neutral fraction was run through a pasteur pipette column $(90 \mathrm{~mm} \times 4 \mathrm{~mm}$ internal diameter) with activated silica gel $(1 \mathrm{~g})$, using hexane $(5.5 \mathrm{~mL})$ as the mobile phase. The neutral fraction was further cleaned up using a silica gel/sulfuric acid column $(2: 1$, $\mathrm{w}: \mathrm{w}, 0.5 \mathrm{~g})$ with hexane $(8 \mathrm{~mL})$ as the mobile phase. The phenolic fraction was treated in the same way as described by Hovander et al. (21). Blank samples $(n=9)$ were run in parallel. Recoveries of the internal surrogate standards $\mathrm{CB} 189$ and 4-OH-CB193 were 83\% (SD 5.1, $n=36$ ) and $88 \%$ (SD 9.5, $n=36$ ), which is in agreement with earlier studies (21).

Table 1. Reference substances and internal surrogate standard (IS) used for quantification of PCBs and $\mathrm{OH}-\mathrm{PCBs}$ in the human serum samples.

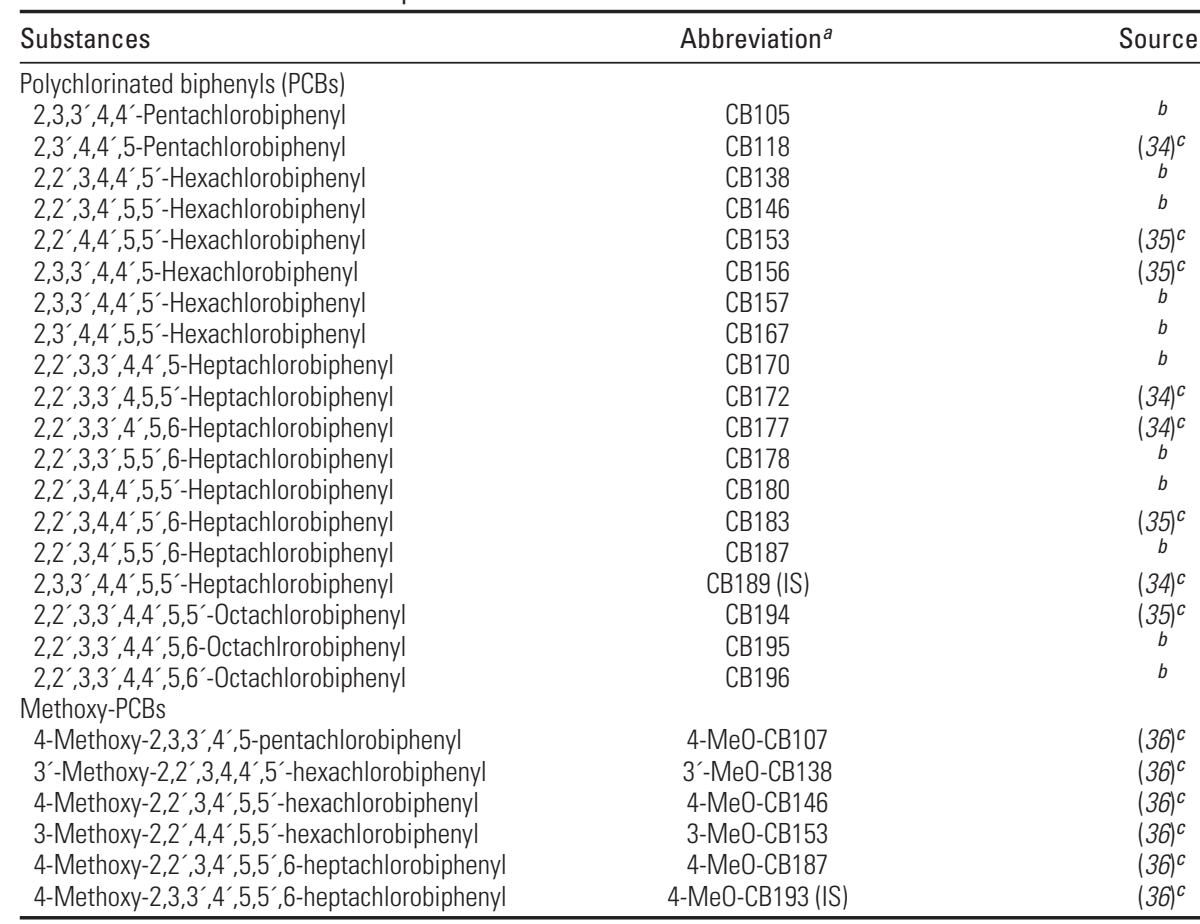

aAbbreviation according to PCB numbering system (37); Me0-PCBs were numbered according to Letcher et al. (9). ${ }^{b}$ Promochem AB, Ulricehamn, Sweden. ${ }^{c}$ Synthesized according to the reference given.

Table 2. Concentrations (ng/g lipid weight and $\mathrm{ng} / \mathrm{g}$ fresh weight) of OH-PCB congeners in serum from pregnant women from the Faroe Islands according to recent pilot whale blubber consumption.

\begin{tabular}{|c|c|c|c|c|c|c|c|c|}
\hline \multirow[b]{3}{*}{ Compound } & \multicolumn{4}{|c|}{ Concentration (ng/g lipid weight) } & \multicolumn{4}{|c|}{ Concentration (ng/g fresh weight) } \\
\hline & \multicolumn{2}{|c|}{ Low $^{a}$} & \multicolumn{2}{|c|}{ Moderate/high ${ }^{b}$} & \multicolumn{2}{|c|}{ Low $^{a}$} & \multicolumn{2}{|c|}{ Moderate/high ${ }^{b}$} \\
\hline & Median & $80 \%{ }^{c}$ & Median & $80 \%{ }^{c}$ & Median & $80 \%{ }^{c}$ & Median & $80 \%{ }^{c}$ \\
\hline Lipid (\%) & 0.78 & $0.67-0.97$ & 0.83 & $0.64-1.00$ & & & & \\
\hline 4-OH-CB107 & 12 & $5.1-73$ & 71 & $41-230$ & 0.084 & $0.041-0.63$ & 0.49 & $0.29-1.7$ \\
\hline 3-OH-CB153 & 13 & $4.0-75$ & 64 & $16-190$ & 0.10 & $0.031-0.58$ & 0.49 & $0.11-1.3$ \\
\hline 4-OH-CB146 & 23 & $9.8-170$ & 120 & $13-270$ & 0.15 & $0.081-1.4$ & 1.1 & $0.14-1.8$ \\
\hline 3'-OH-CB138 & 13 & $3.5-100$ & 96 & $47-170$ & 0.11 & $0.033-0.84$ & 0.64 & $0.34-1.4$ \\
\hline 4-OH-СB187 & 37 & $18-210$ & 190 & $23-470$ & 0.27 & $0.14-1.6$ & 1.6 & $0.23-3.0$ \\
\hline$\Sigma O H-\mathrm{PCB}^{d}$ & 96 & $39-590$ & 560 & $36-1300$ & 0.75 & $0.34-4.6$ & 5.0 & $0.37-8.1$ \\
\hline
\end{tabular}

The $\mathrm{OH}-\mathrm{PCB}$ congeners are listed in elution order on a CP-Sil 8 column.

${ }^{a} 0-1$ meals/month. ${ }^{b} 2-8$ meals/month. ${ }^{c} 80 \%$ range (10th-90th percentiles). ${ }^{d}$ Sum of the OH-PCBs shown. 
were detected, representing other $\mathrm{OH}-\mathrm{PCB}$ and dihydroxylated PCB congeners (10).

The serum concentrations, medians, and 80th percentile ranges of 18 PCB congeners, along with the $\Sigma$ PCB (sum of detected congeners), are presented in Table 3. CB153 shows a concentration range of $35-2,200 \mathrm{ng} / \mathrm{g}$ lw and 58-5,700 ng/g lw in the low and moderate/high pilot whale blubber consumption groups, respectively, while $\Sigma \mathrm{PCB}$ ranges are 150-9,000 ng/g lw and 280-22,000 ng/g lw.

\section{Discussion}

This study amplifies previous evidence that increased PCB exposures occur in the Faroe Islands. In addition, new evidence is presented that $\mathrm{OH}-\mathrm{PCB}$ occur in conjunction with the PCB congeners normally observed as a result of dietary exposure to OHSs. As recently reported, likely sources of OHS exposures in the Faroe Islands are pilot whale blubber and muscle, wild birds, and bird eggs $(22,23)$. This study did not attempt to quantify lifetime intakes of blubber or alternative exposure sources.

Instead, subjects were divided into two groups in relation to their recent consumption of pilot whale blubber, the only dietaryrelated parameter available describing potentially different exposures to persistent organic pollutants and their metabolites. This division provided reasonable numbers of subjects in each category. When more information becomes available on OHS concentrations in Faroese subsistence foods and the actual intake

Table 3. Concentrations (ng/g lipid weight) of 18 PCB congeners in serum from pregnant women from the Faroe Islands.

\begin{tabular}{|c|c|c|c|c|}
\hline \multirow[b]{2}{*}{ Compound } & \multicolumn{2}{|c|}{ Low (0-1 meals/month) } & \multicolumn{2}{|c|}{ Moderate/high (2-8 meals/month) } \\
\hline & Median & $80 \%^{a}$ & Median & $80 \%^{a}$ \\
\hline Lipid (\%) & 0.78 & $0.67-0.97$ & 0.83 & $0.64-1.0$ \\
\hline \multicolumn{5}{|c|}{ Polychlorinated biphenyls } \\
\hline CB118 & 48 & 24-460 & 360 & $46-780$ \\
\hline CB146 & 28 & $16-200$ & 210 & $18-360$ \\
\hline CB153 & 190 & $130-1,500$ & 1,500 & $130-3,000$ \\
\hline CB105 & 11 & $4.2-90$ & 78 & $12-160$ \\
\hline CB138 & 140 & $94-1,100$ & 1,100 & $110-1,900$ \\
\hline CB178 & 13 & $6.5-94$ & 85 & $7.0-160$ \\
\hline CB187 & 66 & $35-520$ & 520 & $42-1,000$ \\
\hline CB183 & 15 & $9.8-120$ & 130 & $12-260$ \\
\hline CB167 & 9.9 & $5.6-77$ & 68 & $8.6-120$ \\
\hline CB177 & 17 & $10-130$ & 140 & $14-280$ \\
\hline CB156 & 18 & $11-150$ & 130 & $13-300$ \\
\hline CB157 & 5.0 & $2.7-36$ & 37 & $2.8-75$ \\
\hline CB172 & 7.8 & $3.9-61$ & 56 & $3.7-110$ \\
\hline CB180 & 120 & $67-980$ & 890 & $61-2,300$ \\
\hline CB170 & 46 & $27-330$ & 300 & $24-740$ \\
\hline CB196 & 11 & $4.3-130$ & 110 & $2.9-340$ \\
\hline CB195 & 4.8 & $2.7-35$ & 34 & $2.9-90$ \\
\hline CB194 & 20 & $9.1-150$ & 120 & $8.2-330$ \\
\hline$\Sigma \mathrm{PCB}^{b}$ & 750 & $460-5,900$ & 5,900 & $510-12,000$ \\
\hline
\end{tabular}

The PCB congeners are listed in elution order on a DB5 GC-column. a80\% range (10th-90th percentiles). ${ }^{b}$ Sum of the PCBs shown. of these foods, it will be possible to improve the exposure assessment. Nonetheless, the present study shows a major difference in exposures of $\mathrm{OH}-\mathrm{PCB}$ and $\mathrm{PCB}$ depending on the recent intake of pilot whale blubber.

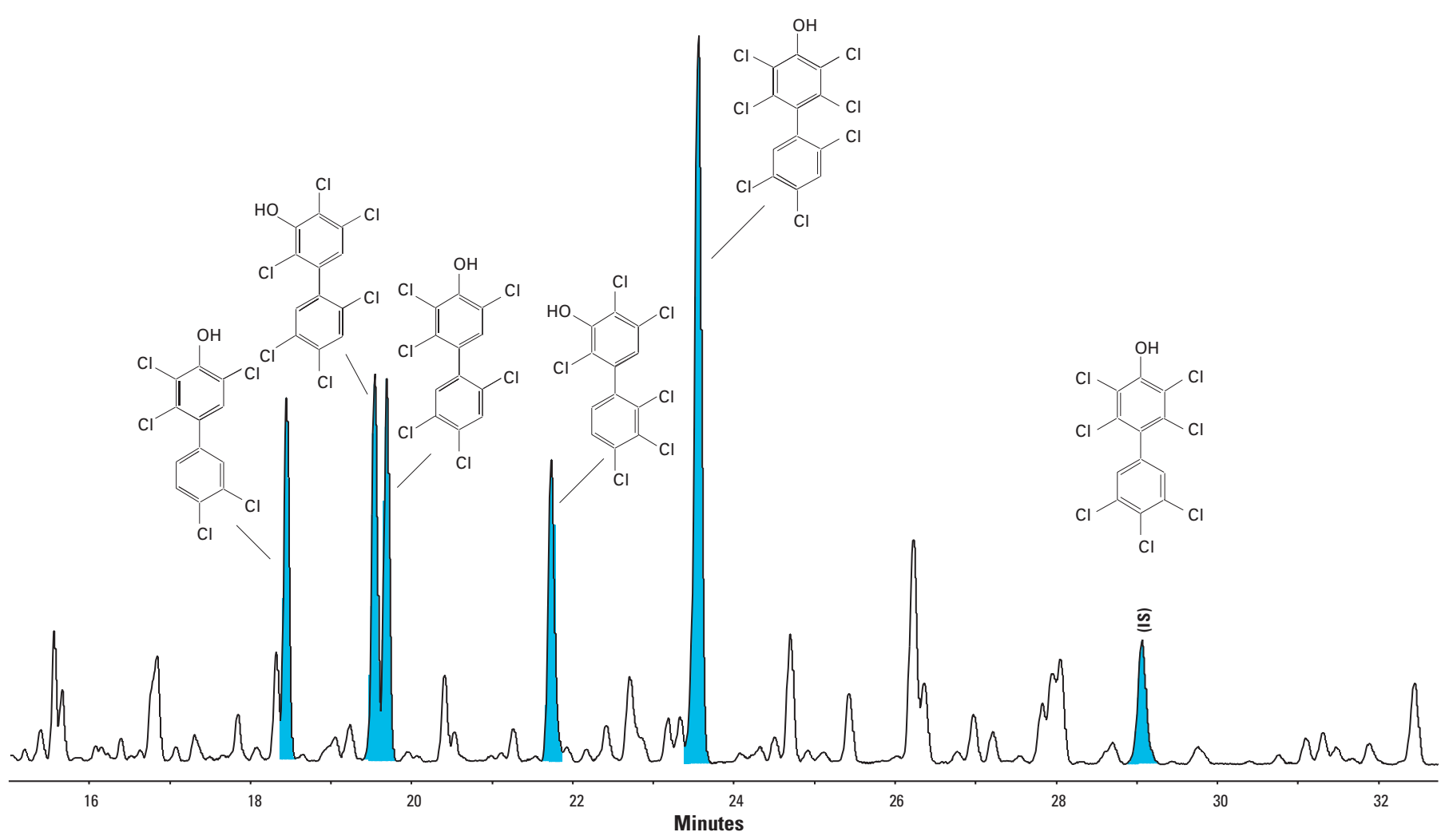

Figure 1. Gas chromatogram (GC/ECD) demonstrating the presence of hydroxylated polychlorinated biphenyls (OH-PCBs) in a serum sample from a Faroese woman with a recent moderate/high pilot whale blubber intake. The concentrations of the six most abundant $\mathrm{OH}-\mathrm{PCBs}$ [4-OH-CB107, 3-OH-CB153, 4-0H-CB146, $3^{\prime}-\mathrm{OH}-\mathrm{CB} 138,4-\mathrm{OH}-\mathrm{CB} 187$, and 4-OH-CB193 (IS)] were determined as their corresponding methyl ethers. The structures of the six most abundant $\mathrm{OH}-\mathrm{PCBs}$ are superimposed in the figure. 
The major $\mathrm{OH}-\mathrm{PCB}$ s identified in the serum samples were 4-OH-CB107, 3-OHCB153, 4-OH-CB146, 3'-OH-CB138 and 4-OH-CB187, the latter being the predominant hydroxylated PCB metabolite. The same metabolites have previously been reported as the major OH-PCBs present in human blood $(5,9,12)$, with $4-\mathrm{OH}-\mathrm{CB} 187$ being the most abundant OH-PCB (12). However, other studies have reported that 4-OH-CB107 was the main metabolite $(5,12)$. The $\mathrm{OH}-\mathrm{PCB}$ peak pattern is shown in Figure 1. Estimation of the total OH-PCB concentrations in the samples indicate that the levels of the five major OH-PCBs account for $90 \%$ of the compounds. The 80 th percentile of $\mathrm{OH}$ PCBs in the moderate/high consumption group $(36-1,300 \mathrm{ng} / \mathrm{g} \mathrm{lw})$ is almost in the same as the 80th percentile for CB153 in the low consumption group (130-1,500 ng/g lw; Tables 2 and 3).

Persistent PCB congeners, such as CB118, CB138, CB153, and CB187, have been shown to form OH-PCB metabolites that are retained in blood (24). Overall, the $\Sigma \mathrm{OH}-\mathrm{PCB}$ concentrations correspond to about $10 \%$ of the $\Sigma$ PCB concentration in the blood serum samples, within a range of about $5-20 \%$. This finding agrees with previous reports at lower $\mathrm{OH}-\mathrm{PCB} / \mathrm{PCB}$ exposures, where average ratios of $10 \%(5,12)$ have been observed (9). This ratio may possibly be higher for persons with relatively low levels of $\mathrm{PCB}$, as indicated in Figure 2. The concentration dependence of the $\mathrm{OH}-\mathrm{PCB} / \mathrm{PCB}$ ratio indicates a faster elimination of $\mathrm{OH}$ $\mathrm{PCB}$ in humans at higher levels of $\mathrm{PCB}$ exposures, which may be explained by induction of phase II enzymes and conjugation reactions (9). However, the possibility also exists that dietary habits may influence the levels of OH-PCB in the body. Marine food such as pilot whale predominantly contains persistent PCB congeners and less of the lower chlorinated and the more rapidly metabolized PCB congeners. The formation

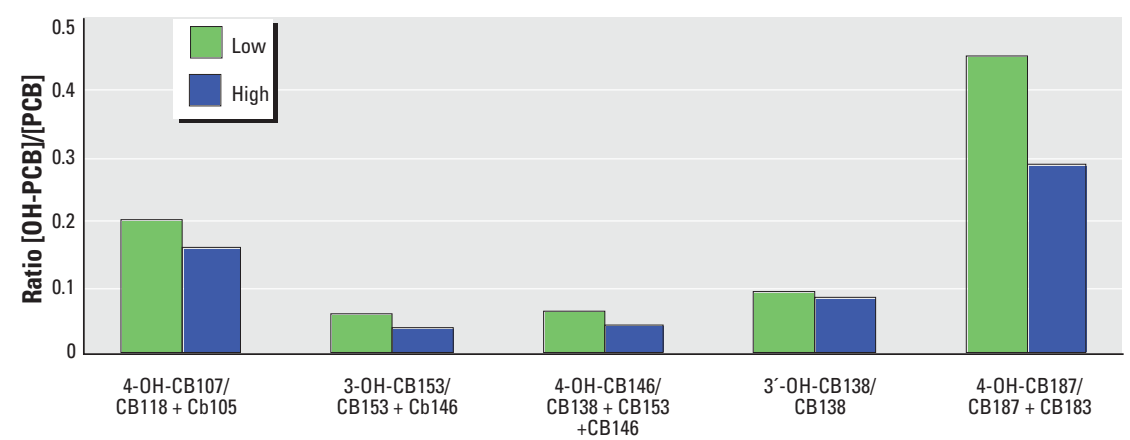

Figure 2. Ratio between $\mathrm{OH}-\mathrm{PCB}$ metabolites and their corresponding parent PCB congener. Subjects were divided into groups according to recent pilot whale blubber consumption: low $=0-1$ blubber meals/month and moderate/high $=2-8$ blubber meals/month.

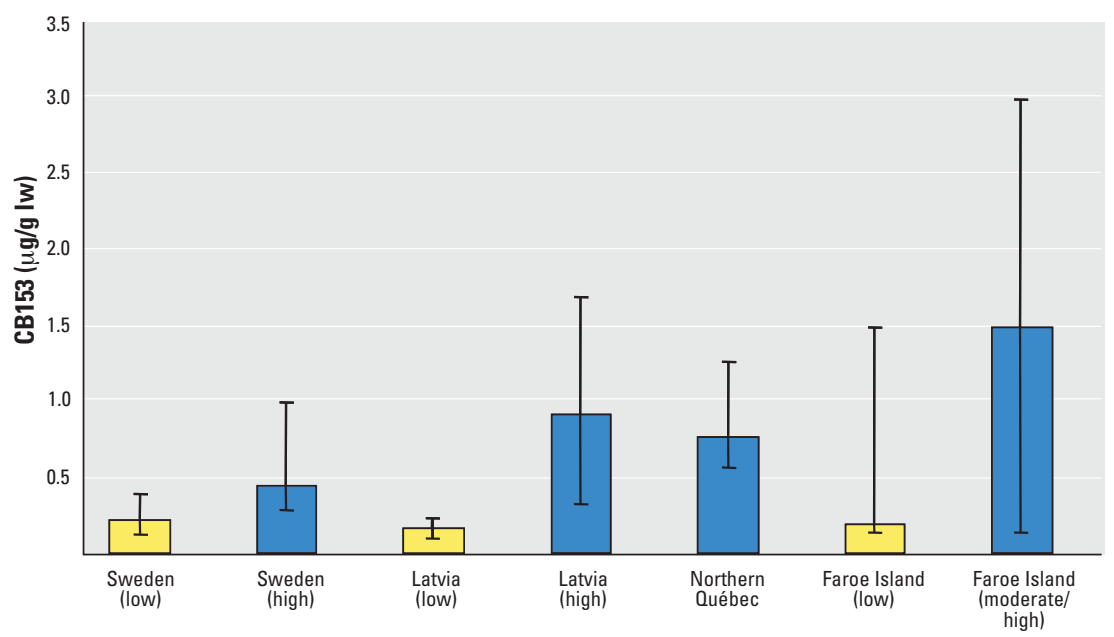

Figure 3. Median concentrations of CB153 ( $\mu \mathrm{g} / \mathrm{g}$ lipid weight) in human plasma samples are given. Error bars indicate the $80 \%$ range (10th-90th percentiles). The Swedish and Latvian male subjects were divided into groups according to consumption of fatty fish: low $=0-1$ fish meals/month and high $\geq 12$ fish meals/month (12). CB153 concentrations in plasma samples from northern Québec men are expressed as plasma equivalents and normalized for lipid content $(5,29,30)$. The CB153 levels in women from the Faroe Islands (present study) were divided into low (0-1 blubber meals/month) and moderate/high (2-8 blubber meals/month). of the $\mathrm{OH}-\mathrm{PCB}$ depends on the metabolism and differences in metabolic capacity between individuals and may thus influence the pattern of $\mathrm{OH}-\mathrm{PCB}$ and their concentrations $(9,25)$. Any conclusions in this regard are hampered by not knowing to what degree the $\mathrm{OH}-\mathrm{PCB}$ are only generated in humans or whether they are also retained from ingested food that contains these compounds, as is the case with eggs (22).

Some toxicologic data have become available on at least one of the OH-PCBs, 4-OH$\mathrm{CB} 107$, which is one of the major $\mathrm{OH}-\mathrm{PCB}$ present in the blood $(9,12,19)$. Thus, lowdose levels of 4-OH-CB107 induce in vivo disturbances in rats, influencing the estrous cycle and behavior of the offspring (19). Current exposure levels of $\mathrm{OH}-\mathrm{PCB}$ as determined in the present study appear to be close to the levels at which effects were observed in the rats. This conclusion is based on the assumption that all halogenated phenolic compounds are as toxic as 4-OH-CB107, an assumption that cannot be confirmed or rejected at this time.

Because of the possible interaction of $\mathrm{OH}-\mathrm{PCB}$ with transthyretine and thyroid metabolism (18), questions regarding the thyroid function have been addressed in the Faroese studies. In the full cohort of children born in 1994, thyroid function was assessed by analysis of serum from the mothers and from the umbilical cord. No association of thyroid hormone parameters with PCB exposure was found ( 7 . In a previous cohort, no association was found between PCB concentrations in cord tissue and thyroxine and thyroid-stimulating hormone in neonatal serum (26). The Faroese rely heavily on a seafood diet, and their iodide intake would therefore likely be in the optimal range, but it is not known whether a high iodide intake may protect against adverse thyroid effects.

Possible adverse health effects have been considered in clinical examinations of Faroese children exposed to PCBs and related OHSs prenatally. Because of concomitant exposure to methylmercury, any neurotoxic effects of PCB have not been readily detectable (27). However, stratified analyses suggest that PCB-associated neurotoxicity may be more apparent when exposure to methylmercury is increased, thus suggesting a possible additive effect (26). In this regard, $\Sigma$ PCB was used as a marker, which reflects a complex exposure that also includes OH-PCBs.

In the serum samples analyzed, CB153 was the most abundant PCB congener, followed by $\mathrm{CB} 138$ and $\mathrm{CB} 180$. The CB153 concentrations correlate well with the $\Sigma \mathrm{PCB}$ concentration $(r=0.999)$, with CB153 accounting for $25 \%$ of the $\Sigma$ PCBs. Similar correlations have also previously been reported (28), although the relative CB153 concentration 
has varied between $25 \%$ and $31 \%$ in previous studies (12,28). Undoubtedly, CB153 is a good indicator for $\Sigma$ PCB concentrations in humans, but it is still important to determine the PCB congener pattern in samples analyzed because this may indicate origin of exposure or give other important details about the exposure.

The CB153 concentrations in the Faroese serum samples are compared to results obtained from Sweden, Latvia, and Arctic Québec in Figure 3. It is notable that the median level of CB153 in the Faroe Islands (moderate/high consumption group) is higher than in any of the other groups and also exceeds the concentrations from the Inuit population from northern Québec $(5,29,30)$. Both the Inuit and the Faroese consume a seafood diet that includes marine mammals and seabirds $(4,25)$. However, the $\Sigma$ PCB concentrations in blubber from ringed seal $(0.96-5.6 \mu \mathrm{g} / \mathrm{g} \mathrm{lw})$ and beluga whale $(0.31-1.5 \mu \mathrm{g} / \mathrm{g} \mathrm{lw})$, which are part of the Inuit diet, are only moderately high $(25,31)$ when compared to $\Sigma$ PCB levels reported for pilot whale blubber $(10-40 \mu \mathrm{g} / \mathrm{g} \mathrm{lw})$ in the Faroese diet (32). Thus, even occasional intake of pilot whale blubber could cause a substantial exposure to PCBs. In this regard, it should be noted that the Faroese intake groups were based on recent dietary habits and that the Faroese may eat whale blubber for dinner (usually with whale meat or dried cod) but also eat thin slices of whale blubber as a snack.

Because of the potential adverse health effects caused by OHS contaminants, a recommendation was issued in 1998 by the Faroese health authorities: "The best way to protect fetuses against the potential harmful effects of PCBs, is if girls and women do not eat blubber until they have given birth to their children" (33). The present results, from samples collected before this statement was issued, reinforce this recommendation. However, further investigations are needed to qualify the present recommendation and to improve the risk assessment.

The present study shows some high concentrations of $\mathrm{OH}-\mathrm{PCB}$ s and $\mathrm{PCB}$ s in human serum, possibly the highest so far reported in a population. The main source of OHS exposures in the Faroe Islands is pilot whale blubber, but consumption of seabirds and their eggs may also contribute to exposure, at least in some cases. It is notable that the Faroese population living in an Atlantic archipelago far away from OHS pollution sources show such high OHS burdens as reported in this study. The $\mathrm{PCB}$ exposure problem is thus not only a matter of the most contaminated areas, such as the Great Lakes and the Baltic Sea, but a worldwide problem linked to dietary habits.

\section{References and Notes}

1. de March BGE, de Wit CA, Muir DCG. Persistent organic pollutants. In: AMAP Assessment Report: Pollution Issues. 0 slo, Norway:Arctic Monitoring and Assessment Programme, 1998:183-371.

2. Bingert $A$, Olsson $M$, Persson W, Jensen $S$, Zakrisson $S$, Litzén K, Eriksson U, Häggberg L, Alsberg T. Temporal trends of organochlorines in northern Europe, 1967-1995. Relation to global fractionation, leakage from sediments and international measures. Environ Pollut 99:177-198 (1998).

3. Norén K, Meironyté D. Certain organochlorine and organobromine contaminants in Swedish human milk in perspective of past 20-30 years. Chemosphere 40:1111-1123 (2000).

4. Ayotte P, Dewailly É, Ryan JJ, Bruneau S, Lebel G. PCBs and dioxin-like compounds in plasma of adult Inuit living in Nuvavik (arctic Québec). Chemosphere 34:1459-1468 (1997).

5. Sandau CD, Ayotte P, Dewailly É, Duffe J, Norstrom RJ. Analysis of hydroxylated metabolites of PCBs and other chlorinated phenolic compounds in whole blood from Canadian Inuit. Environ Health Perspect 34:3871-3877 (2000).

6. Grandjean $\mathrm{P}$, Weihe $\mathrm{P}$, Needham LL, Burse VW, Patterson JDG, Sampson EJ, Jorgensen PJ, Vahter M. Relation of a seafood diet to mercury, selenium, arsenic and polychlorinated biphenyl and other organochlorine concentrations in human milk. Environ Res 71:29-38 (1995).

7. Steuerwald U, Weihe P, Jorgensen PJ, Bjerve K, Brock J Heinzow B, Budtz-Jorgensen E, Grandjean P. Maternal seafood diet, methylmercury exposure, and neonatal neurologic function. J Pediatrics 136:599-605 (2000).

8. Asplund L, Svensson B-G, Nilsson A, Eriksson U, Jansson $B$, Jensen S, Wideqvist U, Skerfving S. Polychlorinated biphenyls, 1,1,1-trichloro-2,2-bis( $p$-chlorophenyl)ethane ( $p, p^{\prime}$-DDT) and 1,1-dichloro-2,2-bis( $p$-chlorophenyl)-ethylene $\left(p, p^{\prime}-\mathrm{DDE}\right)$ in human plasma related to fish consumption. Arch Environ Health 49:477-486 (1994).

9. Letcher RJ, Klasson-Wehler E, Bergman A. Methyl sulfone and hydroxylated metabolites of polychlorinated biphenyls. In: The Handbook of Environmental Chemistry: New Types of Persistent Halogenated Compounds, Vol 3 (Paasivirta J, ed). Berlin:Springer-Verlag, 2000:315-359.

10. Hovander L, Malmberg T, Athanasiadou M, Bergman $\AA$, Rahm S, Klasson Wehler E. Identification of hydroxylated PCB metabolites and other phenolic pollutants in human blood plasma. Arch Environ Contam Toxicol 42:105-117 (2002).

11. Sandau CD, Ramsay MA, Norstrom RJ. Implications of hydroxylated metabolites of PCBs and other halogenated phenolic compounds as endocrine disruptors in polar bears. In: Proceedings of the Third Biennial International Conference on Chemical Measurement and Monitoring of the Environment (Clement R, Burk B, eds). Ottawa Ontario, Canada:EnviroAnalysis 2000 Conference Secretariat, 2000;247-252.

12. Sjödin A, Hagmar L, Klasson-Wehler E, Björk J, Bergman $\AA$. Influence of the consumption of fatty Baltic Sea fish on plasma levels of halogenated environmental contaminants in Latvian and Swedish Men. Environ Health Perspect 108:1035-1041 (2000).

13. Asplund L, Athanasiadou M, Sjödin A, Bergman $\AA$, Börjeson H. Organohalogen substances in muscle, egg and blood from healthy Baltic salmon (Salmo salar) and Baltic salmon that produced offspring with the M74 syndrome. Ambio 28:67-76 (1999).

14. Bergman $\AA$, Klasson-Wehler E, Kuroki H. Selective retention of hydroxylated PCB metabolites in blood. Environ Health Perspect 102:464-469 (1994).

15. Jansson B, Jensen S, Olsson M, Renberg L, Sundström G, Vaz R. Identification by GC-MS of phenolic metabolites of PCB and $p, p^{\prime}-D D E$ isolated from Baltic guillemot and seal. Ambio 4:93-97 (1975).

16. Klasson-Wehler E, Bergman $\AA$, Athanasiadou M, Ludwig JP, Auman HJ, Kannan K, Van Den Berg M, Murk AJ, Feyk LA, Giesy JP. Hydroxylated and methylsulfonyl polychlorinated biphenyl metabolites in albatrosses from Midway Atoll, north Pacific Ocean. Environ Toxicol Chem 17:1620-1625 (1998)

17. Olsson A, Ceder K, Bergman $\AA$, Helander B. Nestling blood of the white-tailed sea eagle (Haliaeetus albicilla) as an indicator of territorial exposure to organohalogen compounds-an evaluation. Environ Sci Technol 34:2733-2740 (2000).

18. Olsson P-E, Borg B, Brunström B, Håkansson H, Klasson-Wehler E. Endocrine Disrupting Substances. Stockholm:Swedish Environmental Protection Agency, 1998.

19. Meerts I. In Vitro and In Vivo Interactions of Organohalogens with the Endocrine System - the Role of Metabolites and Implications for Human Health [PhD Thesis]. Wageningen The Netherlands:Department of Toxicology, Wageningen University, 2001.

20. Fieser LF, Fieser M. Reagents for Organic Synthesis. New York:John Wiley and Sons, 1967.

21. Hovander L, Athanasiadou M, Asplund L, Jensen S, Klasson-Wehler E. Extraction and cleanup methods for analysis of phenolic and neutral organohalogens in plasma. J Anal Toxicol 24:696-703 (2000).

22. Fängström $B$, Athanassiadis I, Athanasiadou $M$ Grandjean P, Weihe P, Bergman A. Hydroxylated PCB metabolites in non-hatched Faroe Islands fulmar eggs. Organohalogen Compounds 52:112-115 (2001).

23. Fängström B, Grandjean $P$, Weihe $P$, Athanasiadou M, Bergman $\AA$. Unpublished data.

24. Sjödin A, Tullsten AK, Klasson-Wehler E. Identification of the parent compounds to selectively retained hydroxylated PCB metabolites in rat blood plasma. Organohalogen Compounds 37:365-368 (1998).

25. Sandau CD. Analytical Chemistry of Hydroxylated Metabolites of PCBs and Other Halogenated Phenolic Compounds in Blood and Their Relationship to Thyroid Hormone and Retinol Homeostasis in Humans and Polar Bears [PhD Thesis]. Ottawa, Ontario, Canada:Carleton University, 2001.

26. Grandjean $\mathrm{P}$, Weihe $\mathrm{P}$, Burse VW, Needham LL, Storr-

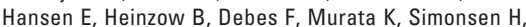
Ellefsen $P$, et al. Neurobehavioral deficits associated with $P C B$ in 7-year-old children prenatally exposed to seafood neurotoxicants. Neurotoxicol Teratol 21:305-317 (2001).

27. Grandjean P, Weihe P, White RF, Debes F, Araki S, Yokoyama K, Murata K, Sorensen N, Dahl R, Jorgensen PJ. Cognitive deficit in 7-year-old children with prenatal exposure to methylmercury. Neurotoxicol Terato 19:417-428 (1997)

28. Grimvall E, Rylander L, Nilsson-Ehle P, Nilsson U Strömberg U, Hagmar L, Östman C. Monitoring of polychlorinated biphenyls in human blood plasma: methodological developments and influence of age, lactation and fish consumption. Arch Environ Contam Toxicol 32:329-339 (1997).

29. Dewailly É, Mulvad G, Henning SP, Ayotte P, Demers A Weber J-P, Hansen JC. Concentration of organochlorines in human brain, liver, and adipose tissue autopsy samples from Greenland. Environ Health Perspect 107:823-828 (1999).

30. Sandau C. Personal communication.

31. Norstrom RJ, Muir DCG. Chlorinated hydrocarbon contaminants in arctic marine mammals. Sci Total Environ 154:107-128 (1994)

32. Borrell A, Aguilar A. DDT and PCB pollution in blubber and muscle of long-finned pilot whales from the Faroe Islands. In: Biology of Northern Hemisphere Pilot Whales (Donovan GP, Lockyer CH, Martin AR, eds). Cambridge, UK:International Whaling Commission, 1993:351-358.

33. Food and Environmental Agency (Faroe Islands). Heilsufrødliga starvstovan. Document 7-97-0014-36. Dietary Recommendation Concerning Pilot Whale Meat and Blubber. Torshavm, Faroe Islands:Department of Occupational Health, 1998

34. Sundström G. Polychlorinated biphenyls II. Synthesis of some tetra- and pentachlorobiphenyls. Acta Chem Scand 27:600-604 (1973).

35. Bergman $\AA$, Nilsson A, Riego J, Örn U. Synthesis of ${ }^{14} \mathrm{C}$ labeled and unlabelled coplanar polychlorinated biphenyls (PCBs). Acta Chem Scand 44:1071-1076 (1990).

36. Bergman $\AA$, Klasson-Wehler E, Kuroki H, Nilsson A. Synthesis and mass spectrometry of some methoxylated PCB. Chemosphere 30:1921-1938 (1995).

37. Ballschmiter K, Mennel A, Buyten J. Long chain alkylpolysiloxanes as non-polar stationary phases in capillary gas chromatography. Fresenius J Anal Chem 346:396-402 (1993). 